\title{
Effects of Cognitive and Non-Cognitive Skills on Employment Conditions of the Tertiary Graduates
}

\author{
Mushfek-Ul-Alam Chowdhury ${ }^{1 *}$, Md. Aynul Islam² \\ ${ }^{1}$ Bangladesh University of Professionals (BUP), Dhaka, Bangladesh \\ ${ }^{2}$ Department of Economics, Jagannath University, Dhaka, Bangladesh \\ Email: *mushfek261978@gmail.com
}

How to cite this paper: Chowdhury, M.-U.-A., \& Islam, Md. A. (2021). Effects of Cognitive and Non-Cognitive Skills on Employment Conditions of the Tertiary Graduates. Journal of Service Science and Management, 14, 530-539.

https://doi.org/10.4236/jssm.2021.145033

Received: August 25, 2021

Accepted: October 17, 2021

Published: October 20, 2021

Copyright $\odot 2021$ by author(s) and Scientific Research Publishing Inc. This work is licensed under the Creative Commons Attribution International License (CC BY 4.0).

http://creativecommons.org/licenses/by/4.0/

\begin{abstract}
Background: Employment has become a very sensitive issue for the graduates at the recent time. Some critics argue that it is the failure of the firms who don't create enough jobs for highly skilled people. But there are those who oppose this idea, believing that educational institutions are failing to prepare the candidates adequately for better jobs. And so, a graduate requires skills beyond academic qualifications to compete in the job market. Following this argument, the authors conducted an empirical investigation by setting up a regression model to see the effects of changes in cognitive and non-cognitive skills on job searching period. Next, the authors examined the effects of job searching period and selective cognitive, non-cognitive factors on employment outcome in a binary logistic model. Aim of the Study: This study was conducted to see the effects of changes in cognitive and non-cognitive skills on job searching period. Another aim was to observe the effects of job searching period and selective cognitive, non-cognitive factors on employment outcome in a binary logistic model. Methods: For the current paper, only Bachelor degree holders were included in the sample. Based on the assumption of the normality test, the data seemed to have a non-normal distribution. As a result, the authors applied log-transformation method in order to convert the data into natural log units. Likert scale method was used to collect primary data on non-cognitive skills in a survey research method that used a questionnaire instrument. Few important variables which are examined by other authors such as field of study, institutional reputation were excluded from the current model and it might have produced some bias in the results but time constraint was a big limitation. Results: It was primarily found that not all non-cognitive factors were significant for changes in job searching periods. However, the binary model dictates a significant relation-
\end{abstract}


ship among the employment outcomes, job searching period and emotional intelligence (non-cognitive factor). Bachelor results and categories of education were included as proxy variables to represent the cognitive level of the respondents. Conclusion: Graduates must emphasize to develop their non-cognitive skills other than academic qualifications. Universities, schools, colleges and other institutions must undertake special programs to develop and to evaluate non-cognitive skills of the graduates other than their academic results in order to prepare them adequately for the future job market.

\section{Keywords}

Cognitive, Non-Cognitive, Job Searching Period, Unemployment, Binary Model

\section{Introduction}

Employment is a major concern among all graduates. People obtain education in order to get monetary return from the labor market. Without a satisfactory return, there will be a guaranteed decline in the value of investment on higher education. Although with higher level of education, one may expect to get jobs very easily but the reality is somewhat different. According to a study by Bhattacharya (2018) even two years earlier, more than one third (34\%) of the young graduates remained unemployed, and currently the rate has gone up to almost 40\% in Bangladesh (Bhattacharya, 2018). Most expertise blame supply side of the labor economy that arises from low quality education and others believe that firms are unable to create enough jobs for the educated youth, which is a demand side problem. But whichever it might be, there is only one universal truth: "without the right skills" one can't accommodate himself in the labor market even if he or she has a higher academic degree. Because firms always consider the individual productivity and overall profitability as they try to minimize the cost of hiring and to maximize revenue from the production processes but lack of job relevant skills on employee's part may lead to mismatch of a job role between firms and graduates. According to Saadat and Khatun, the process of job creation and job destruction in any labor market are based on a matching procedure that may involve hiring unemployed graduates, and there can be a significant lag in the process when there is an extensive amount of skill mismatch (Khatun \& Saadat, 2020). Some other authors define this problem as "skill gap". As revealed in previous studies, "skill gap" is likely to exist in Bangladeshi labor market which makes the market inefficient (Murshid, 2016).

It mainly occurs due to the ongoing structural transformation leading to regular alteration of employer's need and job requirements. Based on the above findings, the author believes that the current problem of increasing unemployment among the tertiary graduates is largely related to under-skilling or skill shortage or perhaps skill gaps that lead to potential mismatch between skills a 
graduate possesses and skills which employers want. McGuiness, Pouliakas and Redmond observed in their study that skill mismatch is often discussed by the policy makers. After considering such evidences, the authors firmly believe that one may describe the consequence of massive unemployment among the tertiary graduates as an outcome either under-skilling or over-skilling. The aim of the study was to measure the effects of changes in cognitive and non-cognitive skills on employment conditions of the tertiary graduates by measuring their job searching periods. The study also measured the effects of different job searching periods, categories of education and selective cognitive and non-cognitive factors on employment outcomes. In addition, the study suggested the policies on the role of specific cognitive and non-cognitive skills which are proved significant from the model.

\section{Methods}

This was a mixed method research study conducted with graduates who held a minimum of Bachelor degree and had studied either in a private or a public university (Institutions which are enlisted by UGC-University grant commission) since 2016-2017. Convenient sampling method was used for the selection of the sample size, and the sample size was determined as 80 with a confidence level of $95 \%$. Therefore, the value of $\mathrm{p}<0.05$ is taken to significant. The research design was a survey method, where a pre-prepared questionnaire model was used to collect both primary and secondary data via email. Emotional intelligence, communication skill, leadership skill, motivation, team management, creativity, negotiation skill; all of these were recognized as non-cognitive skills, and academic results were recognized as cognitive skills. Multiple regression technique and binary logistic were used to create a score system for non-cognitive skills.

\section{Results}

From the above model summary, it was found by the authors that the $R^{2}$ of the model was $45.8 \%$. With this one may arrive to this conclusion that $45.8 \%$ of the total variation in length of average job searching period for both employed and unemployed graduates can be explained by the regression model. Adjusted $R^{2}$ implies the model is currently adjusted by $36 \%$ for all the independent variables which are included. According to the findings, The Durbin-Watson statistic is 2.020 which are between 1.5 and 2.5 and therefore the data is not auto correlated [Table 1]. It is to be noted that the F-value is the Mean Square Regression (1.065) divided by the Mean Square Residual (.222), yielding $F=4.78$. The $\mathrm{p}$-value associated with this $\mathrm{F}$ value was very small (0.000). Further, these values were used to conclude that the independent variables reliably predict the dependent variables [Table 2]. The above results show that SSC results, emotional intelligence and interpersonal communication ability have statistical significance ( $\mathrm{p}<0.05)$ effect on job searching period. Which can be interpreted as, for $1 \log$ unit change in the SSC results there seems to be an average of 4.565 positive log 
Table 1. Model summary.

\begin{tabular}{ccccccccccc}
\hline \multirow{2}{*}{ Model } & \multirow{2}{*}{$\mathbf{R}$} & \multirow{2}{*}{ R Square } & \multirow{2}{*}{$\begin{array}{c}\text { Adjusted } \\
\text { R Square }\end{array}$} & \multirow{2}{*}{$\begin{array}{c}\text { Std. Error } \\
\text { of the Estimate }\end{array}$} & \multicolumn{5}{c}{ Change Statistics } \\
\cline { 6 - 8 } & & & & R Square Change & F Change & df1 & df2 & Sig. F Change & Durbin-Watson \\
\hline 1 & $0.677^{\mathrm{a}}$ & 0.458 & 0.362 & 0.47162 & 0.458 & 4.786 & 9 & 51 & 0 & 2.02 \\
\hline
\end{tabular}

apredictors: (Constant), COMMln, HSCln, TWln, EIln, SSCln, CRln, MOTln, LEADNEGln, Bln; ${ }^{\mathrm{b} D e p e n d e n t ~ V a r i a b l e: ~ J S l n . ~}$

Table 2. ANOVA ${ }^{\mathrm{a}}$.

\begin{tabular}{ccccccc}
\hline \multicolumn{1}{c}{ Model } & Sum of Squares (SS) & df & Mean Square & F & Sig. \\
\hline \multirow{3}{*}{1} & Regression & 9.582 & 9 & 1.065 & 4.786 & $0.000^{\mathrm{b}}$ \\
& Residual & 11.344 & 51 & 0.222 & & \\
& Total & 20.925 & 60 & & &
\end{tabular}

aDependent Variable: JSln; ' Predictors: (Constant), COMMln, HSCln, TWln, EIln, SSCln, CRln, MOTln, LEADNEGln, Bln. From the co-efficient table, the model can be written in the following empirical form: $\gamma$ $=\ln \_$JS $($job searching period $)=-0.618+\operatorname{Ln} 4.565 \mathrm{ssc}+\operatorname{Ln} 0.078 \mathrm{Hsc}-\operatorname{Ln} 1.657 \mathrm{~B}+\operatorname{Ln} .366 \mathrm{EI}-\mathrm{Ln} .062 \mathrm{CR}$ + Ln.535 MOT + Ln.585 LEADNEG + Ln.111 TW - Ln.516 COMM + $\varepsilon$.

unit changes in the length of job searching period (increases), for 1 log unit change in the scale of emotional intelligence there seems to be an average of.366 positive log unit changes in the length of job searching period (With lesser emotional intelligence job searching period increases) and for 1 log unit change in the scale of interpersonal communication ability there seems to be an average of -0.516 negative log units of changes in the length of job searching period. On the other hand, Bachelor result, leadership and negotiation skills and motivation have no statistical significance ( $p>0.05$ ) on job searching period. Which can be interpreted as, for $1 \log$ unit change in the Bachelor results there seems to be an average of -1.657 negative log unit changes in the length of job searching period (A higher CGPA helps in shortening the duration of job searching), for 1 log unit change in the scale of leadership and negotiation skills results there seems to be an average of 0.585 positive log unit changes in the length of job searching period (a lesser negotiation skills increases average job searching period) and for 1 log unit change in the scale of motivation there happens to be an average of 0.535 positive log unit changes in the length of job searching period [Table 3]. Even though there are no significant changes in the $R^{2}$ of the model but the adjusted $R^{2}$ has increased slightly. The signs of the beta co-efficient are remaining unchanged and now, all of them are highly significant now at $\mathrm{P} \leq 0.05$ level [Table 4]. The F-values are still significant, there is still no auto-colineiarity and the independent variables are reliably predicting the outcome of the model whereas the model overall predicts almost a perfect dataset that has a closer proximity to the original regression line [Table 5]. The $\mathrm{R}^{2}$ values tell the researcher approximately how much variation in the outcome is explained by the model. Nagelkerke's $R^{2}$ suggests that the model explains roughly $75 \%$ of the variation in the outcome. Further, Cox and Snell's $R^{2}$ are based on the log likelihood for the model compared to the log likelihood of a baseline model. However, with categorical outcomes, it has a theoretical maximum value of less than 1 , even for a "perfect" 
Table 3. Coefficients.

\begin{tabular}{|c|c|c|c|c|c|c|c|c|c|c|}
\hline \multirow{2}{*}{ Model } & \multicolumn{2}{|c|}{ Unstandardized Coefficients } & \multirow{2}{*}{$\begin{array}{l}\text { Standardized } \\
\text { Coefficients } \\
\text { Beta }\end{array}$} & \multirow{2}{*}{$\mathrm{t}$} & \multirow{2}{*}{ Sig. } & \multicolumn{3}{|c|}{ Correlations } & \multicolumn{2}{|c|}{ Collinearity Statistics } \\
\hline & B & Std. Error & & & & Zero-order & Partial & Part & Tolerance & VIF \\
\hline (Constant) & -0.618 & 2.039 & & -0.303 & 0.763 & & & & & \\
\hline SSCln & 4.565 & 1.46 & 0.411 & 3.127 & 0.003 & 0.294 & 0.401 & 0.322 & 0.616 & 1.622 \\
\hline HSCln & 0.078 & 1.36 & 0.01 & 0.058 & 0.954 & 0.383 & 0.008 & 0.006 & 0.335 & 2.983 \\
\hline$B \ln$ & -1.657 & 0.908 & -0.292 & -1.825 & 0.074 & 0.081 & -0.248 & -0.188 & 0.416 & 2.405 \\
\hline EIln & 0.366 & 0.158 & 0.28 & 2.319 & 0.024 & 0.395 & 0.309 & 0.239 & 0.73 & 1.369 \\
\hline CRln & -0.062 & 0.26 & -0.029 & -0.238 & 0.813 & 0.027 & -0.033 & -0.024 & 0.701 & 1.426 \\
\hline LEADNEGln & 0.585 & 0.329 & 0.278 & 1.778 & 0.081 & 0.396 & 0.242 & 0.183 & 0.433 & 2.308 \\
\hline MOTln & 0.535 & 0.28 & 0.264 & 1.91 & 0.062 & 0.222 & 0.258 & 0.197 & 0.555 & 1.8 \\
\hline TWln & 0.111 & 0.219 & 0.069 & 0.505 & 0.616 & 0.169 & 0.071 & 0.052 & 0.572 & 1.749 \\
\hline COMMln & -0.516 & 0.243 & -0.329 & -2.123 & 0.039 & -0.202 & -0.285 & -0.219 & 0.442 & 2.265 \\
\hline
\end{tabular}

Removal of non-significant factors.

Table 4. Regression model.

\begin{tabular}{cccccc}
\hline & Sum of Squares & df & Mean Square & F & Sig. \\
\hline Regression & 9.522 & 6 & 1.587 & 7.515 & $0.000^{\mathrm{b}}$ \\
Residual & 11.404 & 54 & 0.211 & & \\
Total & 20.925 & 60 & & & \\
\hline
\end{tabular}

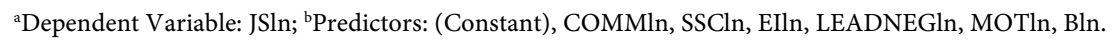

Table 5. Model Summary non-significant factors are removed.

\begin{tabular}{|c|c|c|c|c|c|c|c|c|c|}
\hline \multirow{2}{*}{$\mathbf{R}$} & \multirow{2}{*}{ R Square } & \multirow{2}{*}{$\begin{array}{l}\text { Adjusted } \\
\text { R Square }\end{array}$} & \multirow{2}{*}{$\begin{array}{l}\text { Std. Error of } \\
\text { the Estimate }\end{array}$} & \multicolumn{5}{|c|}{ Change Statistics } & \multirow{2}{*}{$\begin{array}{c}\text { Dur- } \\
\text { bin-Watson }\end{array}$} \\
\hline & & & & R Square Change & F Change & df1 & df2 & Sig. F Change & \\
\hline $0.675^{\mathrm{a}}$ & 0.455 & 0.394 & 0.45954 & 0.455 & 7.515 & 6 & 54 & 0.000 & 2.072 \\
\hline
\end{tabular}

aPredictors: (Constant), COMMln, SSCln, EIln, LEADNEGln, MOTln, Bln; ${ }^{b}$ Dependent Variable: JSln.

model whereas Nagelkerke's $R^{2}$ is an adjusted version of the Cox \& Snell $\mathrm{R}$-square that adjusts the scale of the statistic to cover the full range from 0 to 1 [Table 6]. From the above table, the researcher may summarize the following: the proportion of variance in the employment outcomes are associated with education, job searching period and emotional intelligence by $74 \%$, indicating that more of the variation is explained by this model that excluded many of the earlier non-cognitive constructs included in the regression model. These values are also called pseudo r-squares [Table 7]. The Hosmer and Lemeshow test is basically a way of ascertaining how well the data fits the model. It is calculated using the deviance of $(-2 \mathrm{LL})$ and produces a p-value based on a chi-square distribution. It tests the null hypothesis that the model is a good enough fit for the data. And, one may only reject the null hypothesis if $\mathrm{p}<0.05$. The Hosmer-Lemeshow statistic indicates a $\mathrm{p}$ value $=(0.906>0.05)$. Based on the $\mathrm{p}$ value, the researcher 
Table 6. Coefficients After removal of non-significant factors.

\begin{tabular}{|c|c|c|c|c|c|c|c|c|c|c|}
\hline & \multicolumn{2}{|c|}{ Unstandardized Coefficients } & \multirow{2}{*}{$\begin{array}{l}\text { Standardized } \\
\text { Coefficients } \\
\text { Beta }\end{array}$} & \multirow{2}{*}{$\mathbf{t}$} & \multirow{2}{*}{ Sig. } & \multicolumn{3}{|c|}{ Correlations } & \multicolumn{2}{|c|}{ Collinearity Statistics } \\
\hline & B & Std. Error & & & & Zero-order & Partial & Part & Tolerance & VIF \\
\hline (Constant) & -0.511 & 1.798 & & -0.284 & 0.777 & & & & & \\
\hline SSCln & 4.565 & 1.334 & 0.411 & 3.421 & 0.001 & 0.294 & 0.422 & 0.344 & 0.701 & 1.427 \\
\hline$B \ln$ & -1.675 & 0.795 & -0.295 & -2.108 & 0.04 & 0.081 & -0.276 & -0.212 & 0.515 & 1.942 \\
\hline EIln & 0.365 & 0.153 & 0.279 & 2.394 & 0.02 & 0.395 & 0.31 & 0.24 & 0.742 & 1.347 \\
\hline LEADNEGln & 0.65 & 0.246 & 0.309 & 2.64 & 0.011 & 0.396 & 0.338 & 0.265 & 0.736 & 1.36 \\
\hline MOTln & 0.549 & 0.267 & 0.271 & 2.054 & 0.045 & 0.222 & 0.269 & 0.206 & 0.579 & 1.728 \\
\hline COMMln & -0.505 & 0.203 & -0.323 & -2.482 & 0.016 & -0.202 & -0.32 & -0.249 & 0.597 & 1.674 \\
\hline
\end{tabular}

${ }^{a}$ Dependent Variable: JSln. Binary Logistic Model: Employment outcomes. The model which is examined by the researcher in the above context is as follows: $\gamma=($ Employment $)=\alpha+\beta_{1}$ Length_of_Job_search $+\beta_{2}$ Ln_ME $+\beta_{2}$ Education $+\varepsilon$. Ln (odds of employment outcome) $=7.657+0.010$ Lnth_job_srch + 1.983MEmotion - 34.473 Education (1) - 14.459 Education (2) - 14.099 Education (3) - 11.598 Education (4) - 18.112 Education (5).

Table 7. Model summary.

\begin{tabular}{cccc}
\hline Step & -2 Log likelihood & Cox \& Snell R Square & Nagelkerke R Square \\
\hline 1 & $29.532^{\mathrm{a}}$ & 0.468 & 0.740 \\
\hline
\end{tabular}

aEstimation terminated at iteration number 20 because maximum iterations have been reached. Final solution cannot be found.

Table 8. Hosmer and Lemeshow Test.

\begin{tabular}{ccc}
\hline Chi-square & df & Sig. \\
\hline 3.410 & 8 & 0.906 \\
\hline
\end{tabular}

may arrive to this conclusion that the model adequately fits the data as the level of significance is well above 0.05 therefore, one may accept the null hypothesis [Table 8]. The above table explains the co-efficient of the model. Length of job searching period and emotional skill seem to be the most significant factor in influencing the binary outcomes of employment situation. The estimated value of beta co-efficient here, in the above model $\left(\beta_{1}\right.$ Lnth_job_srch_14.2 $=0.010 ; \beta_{2}$ ME motion $=0.010$ ) indicate the estimated changes in the log odd from "being in employment situation $=0$ " to "being in unemployment situation $=1$ " for each unit increase in these independent factors. So based on the above findings, the authors may draw this conclusion that the estimated change in the log-odds from "being in employment situation" to "unemployment situation" for each unit increase in job searching period is $=0.010$. And, the estimated change of log-odds from "employment" to "unemployment" situation for each unit increase in emotional intelligence is 1.983 . Both of these variables are statistically highly significant ( $\mathrm{p} \leq 0.05$ ). The model uses "Level of education" (a categorical variable with many subgroups) as a proxy to dictate the level of changes in the cognitive levels instead of academic test results. Hence, the estimated change of the log-odds from "employment" to "unemployment situation" is decreased by 
-34.473 units once a candidate obtains a B.com certificate following his upper-secondary. But these estimated changes of log-odds from "employment" to "unemployment" are decreased only by -14.459 and -14.099 units once he obtains either an M.com or a Bachelor degree [Table 9].

\section{Discussion}

Based on the significance level of the beta co-efficient, each factor which is included in the model ( $\mathrm{p} \leq 0.05$ ) seem highly significant, therefore, the researcher is certainly in a position to answer the research question: "Both cognitive and non-cognitive factors affect the employment conditions (job searching period) of the tertiary graduates". The VIF's and Tolerance levels are not violating any assumptions of "no multicollinearity" (Akanda \& Md, 2018). Uysal, D. S. and Pohlmeier, W. (2011) show that there is a strong relationship between non-cognitive factors and duration of unemployment spell (Uysal \& Pohlmeier, 2011). The current findings also indicated the same. From the above findings, the authors further arrive to the following conclusions: the higher the level of cognitive skills for a graduate at the primary level, the higher is the length of job searching period that he or she experiences due to the kind and nature of jobs which are offered at this level (low-skilled jobs). According to ILO (2013) findings, most of the jobs in manufacturing and construction sector are still either low-skilled or semi-skilled (International Labor Organization, 2013). Results from ADB also support the above findings (Murshid, 2016). Findings from the current research are also quite similar but have a different implication. In the current research, SSC and HSC graduates who didn't continue at the Bachelor level were excluded. One may describe these people as academically highly talented who certainly desire for more advancement in the later stage of their lives and as a result, they probably do not look for a job and remain occupied in progressing their academic career. Also, the more a candidate seems emotionally intelligent; the lower is the length of his job searching period. Further, as a

Table 9. Variables in the equation.

\begin{tabular}{ccccccc}
\hline & B & S.E. & Wald & df & Sig. & Exp (B) \\
\hline Lnth_job_srch_14.2 & 0.010 & 0.004 & 6.833 & 1 & 0.009 & 1.010 \\
MEmotion & 1.983 & 0.715 & 7.685 & 1 & 0.006 & 7.265 \\
Education & & & 10.190 & 5 & 0.070 & 0.000 \\
Education(1) & -34.473 & $56,841.359$ & 0.000 & 1 & 1.000 & 0.000 \\
Education(2) & -14.459 & $40,192.852$ & 0.000 & 1 & 1.000 & 0.000 \\
Education(3) & -14.099 & $40,192.852$ & 0.000 & 1 & 1.000 & 0.000 \\
Education(4) & -11.598 & $40,192.851$ & 0.000 & 1 & 1.000 & 0.000 \\
Education(5) & -18.112 & $40,192.851$ & 0.000 & 1 & 1.000 & 1.000 \\
Constant & 7.657 & $40,192.852$ & 0.000 & 1 & 2115.044 \\
\hline
\end{tabular}

${ }^{a}$ Variable(s) entered on step 1: Lnth_job_srch_14.2, MEmotion, and Education. 
graduate possesses more negotiation and leadership skills, the higher is the possibility that he will find a reasonable job within a short period of time because wage negotiations and coming to an agreement on other terms and conditions such as participation in training programs, opportunities for promotions during an interview process are vital factors for acceptance of job offers. It is to be noted that an increasing average Likert score implies a lower skill based on the current research settings. Finally, it seems candidates who make lesser attempts to communicate about their innate abilities or internal productivity with the employers, job searching period becomes shorter for them. Many firms and candidates in Bangladesh are not adapted to a better screening process; therefore, poor signaling is also a reason for such negative effects of interpersonal communication. Johnes and Johnes showed that signaling is important for revealing the innate abilities of a candidate during a recruitment process (Johnes \& Johnes, 2004). Additionally, candidates with a higher GPA or a higher cognitive level at their bachelor levels are expected to find a job sooner rather than later. Based on the above findings, there is a sufficient evidence to believe that job markets in Bangladesh rely more on external signals such as academic qualifications. Examining the results, the researcher also found that in both situations adjusted $R^{2}$ $<R^{2}$, so some explanatory variables which may better explain the changes in job searching period are definitely missing from the current model. In both of the circumstances the models constitute a negative intercept ( $\alpha=-0.618,-0.511$ ), so the authors presume that there is always a fixed negative change in the average length of job searching period for the graduates due to some other external variables even if there is no change in the selected independent variables (Akanda \& Md, 2018; Gujarati et al., 2016; Greene, 2013). A 2019 study by Chowdhury and Nagashima indicates that many graduates are failing to find a job even after completing their master's degree (Nakata et al., 2018). These estimated negative changes in log-odd possibilities are only -11.099 for those who obtain a master's degree but -18.112 for someone who pursues an academic qualification beyond a master's level. Values of $\beta_{3}$ 's for Education are used as categorical variables, where "last" or the "lowest" value assigned to a sub-group (categories - "upper-secondary" $=0$ ) is used as a reference in order to compare with the other sub-groups. Furthermore, Exp (B) refers to the risk associated with "being in unemployment situation", which is measured in terms of "number of times" for "a unit increase" in specific independent factors. So, based on the above findings the authors might conclude that for 1 unit increase in job searching period the risk of being in unemployment situation increases by 1.010 times more than not being in such situations. In the same manner, for 1 unit increase in emotional intelligence the risk for such odd outcomes increases by 7.265 times (Akanda \& Md, 2018).

Therefore, the findings support the previous evidences to draw the conclusion that in order to avoid unemployment situation a graduate must attempt to cut down the length of his job searching period, also an increase in the units of emotional intelligence is a measurement of a lower skill based on the settings of the Likert scale. Accordingly, candidates with higher emotional intelligence have 
lower possibility of being in unemployment situation that conveys the importance of this non-cognitive factor in avoiding unemployment. Findings from several studies describe non-cognitive factors in terms of personality traits rather than defining in its own term who believe neuroticism is the emotional state of someone that is certainly associated with labor market outcomes (Almlund et al., 2011; Garcia, 2013). Other relevant findings indicate that "Emotional stability" is an important factor that is also dictated by self-esteem and locus of control which also influences educational outcomes (Almlund et al., 2011; Acosta et al., 2015).

\section{Conclusion}

Based on the current results, the researcher believes that the graduates must emphasize to develop their non-cognitive skills other than academic qualifications. Universities, schools, colleges and other institutions must undertake special programs to develop and to evaluate non-cognitive skills of the graduates other than their academic results in order to prepare them adequately for the future job market. An enterprise-based survey (2013) on the assessment of skills of formal labors in the job market of Bangladesh discovers that the current education system doesn't provide the skills which labor market demands and on the other hand, there is a greater need of non-cognitive skills to succeed in the current job market yet current education system doesn't emphasize enough on these types of soft skills.

\section{Recommendations}

Institutions, parents and students should devote enough time to develop non-cognitive skills through formal and informal interaction. Institutions must also invest on formal evaluation and self-learning process to develop the soft skills. The significance of SSC results indicates that candidates who mostly pursue higher studies at the Bachelor or Master's level, have a higher "cognitive level" at the earlier stage of their academic career. To investigate the impact of cognitive and non-cognitive skills on employment outcomes of the graduates in the presence of omitted factors, further research is suggested.

\section{Authors Contributions}

MAC conducted this study with the guidance from MAI.

\section{Source of Funding}

Self.

\section{Approval}

From the respective department.

\section{Conflicts of Interest}

The authors declare no conflicts of interest regarding the publication of this paper. 


\section{References}

Acosta, P, A., Muller, N., \& Miguel, S. (2015). Beyond Qualifications: Returns to Cognitive and Socio-Emotional Skills in Colombia. Institute of Labor Economics, Discussion Paper No. 9403. https://doi.org/10.1596/1813-9450-7430

https://www.semanticscholar.org/paper/Beyond-Qualifications\%3A-Returns-to-Cognit ive-and-in-Acosta-Muller/4e9fa3018b87c272f9d5aba1b0440399da85ffa9

Akanda, S. A., \& Md, D. R. (2018). Statistical Packages for Advanced Data Analysis (pp. 13-27). Bangladesh University of Professionals.

Almlund, M., Duckworth, L, A., Heckman, J., \& Kautz T. (2011). Personality Psychology and Economics. Institute for the Study of Labor (IZA), Discussion Paper No. 5500. http://ftp.iza.org/dp5500.pdf

Bhattacharya, D. (2018, November 4). The Uncomfortable Truth Recent Economic Growth Performance of Bangladesh. Bangladesh Institute of Development Studies. https://bids.org.bd/uploads/Seminar/Abdul\%20Ghafur\%20Memorial\%20Lecture\%2020 18 Lecture\%20by\%20Dr\%20Debapriya\%20Bhattacharya.pdf

Garcia, E. (2013). What We Learn in School: Cognitive and Non-Cognitive Skills in Education Production Function. Doctoral Thesis, Columbia University. https://www.researchgate.net/publication/259183954 What we learn in school Cog nitive and non-cognitive skills in the educational production function

Greene, H. W. (2013). Econometric Analysis (5th ed.). Dorling Kindersley Pvt. Ltd., Licensee of Pearson Education, South Asia.

Gujarati, N. D., Porter, C. D., \& Gunasaker, S. (2016). Basic Econometrics (5th ed.). McGraw Hill Education (India) Private Limited.

International Labor Organization (2013). Seeking Better Employment Conditions for Socio-Economic Outcomes-Economic Performances and Challenges of Creating Jobs (pp. 19-50). International Institute for Labor Studies.

https://www.ilo.org/wcmsp5/groups/public/---dgreports/---dcomm/documents/public ation/wcms 229105.pdf

Johnes, G., \& Johnes, J. (2004). International Handbook on Economics of Education. Series LC65.I59 2004 338.4737_dc22 2004047118, Montpellier Parade Cheltenham Glos, Edward Elgar Publishing Limited. https://doi.org/10.4337/9781845421694

https://is.muni.cz/el/econ/jaro2014/MPV EKVZ/um/46997476/International handboo $\mathrm{k}$ on the economics of education.pdf

Khatun, F., \& Saadat, S. (2020). Youth Employment in Bangladesh-Creating Opportunities, Reaping Dividends. Palgrave Macmillan. https://doi.org/10.1007/978-981-15-1750-1

Murshid, K. A. (2016). Skill Gap Analysis for Selected Sectors (pp. 1-37). BIDS Research Almanac.

Nakata, S., Chowdhury, R. A., Nagashima, Y., Rahman, M., Chowdhury, T., \& Rahman, M. S. (2018). Bangladesh Skills for Tomorrow's Jobs-Preparing Youth for Fast Changing Economy. World Bank (IBRD, IDA), World Bank Office. https://www.researchgate.net/publication/335893207 Bangladesh Preparing Youth fo $\underline{\mathrm{r} \text { a fast Changing Economy }}$

Uysal, D. S., \& Pohlmeier, W. (2011). Unemployment Duration and Non cognitive Skills. Journal of Economic Psychology, 32, 980-992.

https://www.sciencedirect.com/science/article/pii/S0167487011000481

https://doi.org/10.1016/j.joep.2011.03.008 